\title{
Maternal Mortality and
} Morbidity in the Developing World: Personal Reflections and a Profession's Commitment

\section{Thomas E. Elkins, MD}

Department of Obstetrics and Gynecology

University of Michigan Medical Center

Ann Arbor, Michigan

Abstract The realities of maternal mortality and morbidity in the developing world and possible roles for intervention by American physicians are discussed.

$\mathbf{T}$ he first person for whom I ever performed a "C-section" died. It was 1975 in the rain forest of Nigeria.

"So it is in Africa. So it will always be." Those words, spoken since.

She had come to our small hospital with a history of over 3 days of active labor. The fetus had already expired, but the cervix was still less than $6 \mathrm{~cm}$ dilated, and the vertex barely entered the pelvic brim. At laparotomy, the lower uterine segment had vanished anteriorly, and a pool of feces lay beneath the remnants of the posterior lower uterus where rectosigmoid tissue should have been. The posterior bladder wall was a combination of necrotic tissue and hematoma.

Despite surgery, blood, fluids, and antibiotics, her fever never subsided. She was less than 16 years old. She had received a clitoridectomy at age 11 and had been sold into marriage as "the third wife" at age 13. This had been her first of what she hoped would be many pregnancies. She died on the fifth postoperative day.

Over 16 years have passed since that initial shock. Over 2 of those years have been spent in the rural and urban medical centers of West Africa. Countless similar patients have passed through my memory. But the vast magnitude of maternal mortality and morbidity in West Africa remains a shocking part of our world.

In the 1980s, world maternal mortality figures were quoted to be the following (per 1000 births):

- 0.1 for Scandinavia

- 0.3 for the United States

- 2.4 for South and Central America
(C) 1992 by The Jacobs Institute of Women's Health $1049-3867 / 92 / \$ 5.00$ 
- 4.2 for India and Southeast Asia

- 6.4 for Africa.'

In the finest teaching hospitals in Ghana, the maternal mortality averages seven to ten maternal deaths per 1000 births each year. ${ }^{2}$ A study of rural maternal mortality showed that in some of the most remote areas of Ghana, maternal mortality rates soared to $40-70$ per 1000 births, even in $1988 .^{3}$

The causes of maternal mortality in Africa have been documented repeatedly. ${ }^{4,5}$ The five most common causes remain obstructed labor and ruptured uterus, postpartum hemorrhage, pregnancy-induced hypertension, postpartum infection, and septic abortion. ${ }^{6}$ Recent studies from the Komfo Anokye Teaching Hospital in Kumasi, Ghana, continue to confirm these causes. ${ }^{7}$ Indeed, some note little significant change from the Middle Ages in Europe. ${ }^{8}$ Similar maternal mortality rates were noted recently in a religious cult in Indiana that refused prenatal, intrapartum, and postpartum medical care. ${ }^{9}$ In America, this was considered appalling, and it drew great attention. In West Africa, these numbers represent the best efforts of the health care system and go unnoticed by many.

In 7 brief days at a rural hospital site visit in northern Ghana in April 1991 , the range of problems was very apparent. One patient came with longobstructed labor, vulvar edema, and fetal demise. She was treated with antibiotics, fluid resuscitation, and a fetal destructive procedure; she survived. One patient presented 3 days postpartum and died from fulminant hepatic failure. Another patient arrived taking her last gasps, dying from postpartum hemorrhage that began in a village to which no roads exists. Another came with undiagnosed twins. One patient presented with a loss of the perineal body following delivery years before, and one presented with a more recent rectovaginal fistula. Sixteen patients presented with postobstetric vesicovaginal fistulas (VVF) or with continued problems after prior fistula closure. This represents the usual number of difficult fistula patients collected each year for the visiting team.

Five "routine" cesarean deliveries were performed during the week. These were done under local anesthesia, supplemented when necessary by intravenous ketamine and meprobamate. Almost a dozen "routine" deliveries were done by the nurse-midwives during the same time. The vast majority of children being born in the region were delivered at home in the surrounding villages, even though an excellent system of outlying prenatal clinics was managed by public health teams.

Maternal mortality and morbidity-perhaps the major problem of West Africa-has no master and continues to defy control. Worldwide, Rosenfield ${ }^{6}$ notes that 500,000 women die unnecessarily each year from preventable causes in obstetrics and that the vast majority of these occur in the developing world.

Many answers have been proposed for this massive problem. Rosenfield ${ }^{6}$ lists an array of potential solutions, aimed at village-level interventions. Harrison ${ }^{1}$ encourages universal literacy for women that will allow them to understand their plight more clearly and seek prenatal care more actively. Harrison ${ }^{10}$ showed that 219 maternal deaths occurred in 7654 women seen first in labor, whereas only 19 deaths occurred among 15,000 women who had prenatal care. Improved transportation and referral services have also been shown to make a difference in maternal mortality statistics. ${ }^{11}$ In general, appropriate nutrition, patient education, and available health care services all appear to reduce maternal mortality and morbidity. ${ }^{10}$ One of the major unanswered questions in the developing world is whether the well-trained specialists in obstetrics and gynecology can have an effect on maternal mortality and morbidity. A corollary question to this is whether any American-trained specialist 
in obstetrics and gynecology can positively assist in changing maternal mortality and morbidity in the developing world.

The claim that obstetrician-gynecologists can assist in the reduction of maternal mortality and morbidity in the developing world is disputed by a number of concerns about our specialty:

1. There are not enough specialists in obstetrics and gynecology in the developing world to have an impact on such major health problems as maternal mortality and morbidity.

2. Most specialists in obstetrics and gynecology are trained by developed world standards, or train in the developed world at least part of the time.

3. Modern obstetrics and gynecology emphasizes such high technology as laser laparoscopy, fetal monitoring, genetics, in vitro fertilization, and radiation oncology, which would be of little relevance to the developing world.

Despite beneficent thoughts of compassion for persons in the developing world, specialists in developed countries often feel as if they have nothing to offer to those engaged in the battle against maternal mortality and morbidity.

While we bemoan the frustrations encountered in attempting to relate to the problems of the developing world, little changes. Late-stage cervical cancer remains common where no cervical screening programs exist, even for highrisk patients. But any such program meets harsh rebukes from those preferring a strict cost analysis approach to suffering. In fact, however, little has been done to assess the use of technology in limited, reasonable ways in the developing world. Studies, for example, that look at the use of obstetric ultrasound to reduce hospital occupancy for patients with suspected placenta previa or to assist in the management of patients referred for other high-risk problems are waiting to be done. Studies to show the effect of antenatal testing of any kind, for that matter, await those with interest, dedication, and enough contemporary technology to achieve change. Highly skilled, intelligent, dedicated, and well-trained physicians are present in the developing world, but they need the support of a contemporary world to meet the challenges they face.

Approaching a major maternal morbidity problem, VVF, in a contemporary fashion reveals the need for improved techniques and technology to relieve suffering. Although closure rates have markedly increased over the last 100 years for persons with VVF, the percentage of those with persistent, severe problems despite successful fistula closure remain very high. Dr. Ann Ward ${ }^{12}$ of Nigeria suggests that $40-50 \%$ of patients with VVF closures continue to have significant stress incontinence, vaginal atresia, small bladder syndrome, secondary amenorrhea, or voiding dysfunction. New surgical techniques, graft materials, postclosure urodynamic evaluation, and massive efforts to train physicians to repair the huge number of patients with VVF must accompany long-range community health efforts aimed at VVF prevention.

We need not become too embroiled in discussions of the utility of contemporary technology, however. Years of visits to West Africa have made it clear that there is much the "have" nations of the world can do for the "have not," especially when issues are addressed in obstetrics and gynecology.

Recent visits to West Africa, even over the past 3 years, have revealed some medical libraries at major medical schools with no textbooks in obstetrics and gynecology beyond 1958 and certainly no personal libraries of substance owned by individual physicians. Journals do arrive in small quantities after long delays for those very few who can afford them. Nonavailability of reasonable suture material for surgery is commonplace. Number-two, not "2-0," sutures are used for episiotomy repairs, or cesarean sections and hysterectomies in some of the very best centers. More than once we have tied bed- 
sheet strips around patients where no tape existed for postlaparotomy wound dressings. New instruments are cause for rejoicing, and scissors that cut or clamps that close are celebrated almost as much. More than once surgery has been cancelled because of a lack of available oxygen or basic anesthetic agents. We search for new and better ways to "double-glove" in our country, whereas our colleagues in developing countries search frequently for nonused gloves of any kind to wear in surgery at any layer.

Through it all, year after year, the maternal mortality and morbidity rates in West Africa and other developing regions remain unchanged. ${ }^{13}$ It is simply unconscionable to allow such widespread and intense suffering to continue. Members of the public health, midwifery, nursing, and social science communities have entered such struggles with the aid of philanthropic agencies and government funding sources. Beyond limited assistance with contraception and other family planning programs, American obstetricians and gynecologists have done little to combat the Third World problem of maternal mortality and morbidity to date. ${ }^{14}$ Strategies are needed at both the personal and institutional levels for this to change over the next 10-15 years. A few suggestions might include the following:

1. Encourage the study of international health as it relates to obstetrics and gynecology in residency training programs. This could be done by a) including developing world issues in major textbooks, b) supporting resident participation in international electives in the developing world, and c) including international maternal mortality and morbidity data and issues on resident examinations.

2. Encourage direct personal collaboration with and support for obstetric and gynecologic colleagues in the developing world by a) supporting visiting scholars and professors in participation in our residency training programs, b) assisting with research development by offering expertise in research design, statistics, and manuscript preparation, c) assisting in faculty development by sponsoring postgraduate teaching and research programs, and d) saving journal articles, books, and monographs of interest to send on a regular basis.

3. Encourage departmental interaction with teaching programs in the developing world by supporting a faculty position that will have a focus on international health that someone can fill on at least a part-time basis.

4. Encourage hospitals and departments to consider donations of usable contemporary equipment, tests, journals, and even sutures and gauze for continuous exchange with a particular medical center in the developing world and supporting programs to help with the maintenance of the equipment donated.

These suggestions for intervention on the part of individual doctors and institutions admittedly fail to address global concerns for literacy, transportation/referral systems, and family planning. Neither do they concur with the popular theories that concentrating on training persons at the lowest level possible (such as traditional birth attendants and midwives) will solve the maternal mortality and morbidity problems of West Africa. At present, such efforts receive vast amounts of funding, but they have shown minimal effects on the capacity of countries to provide the surgery, antibiotics, and blood replacement necessary to change maternal mortality rates. The specialist is, in effect, almost isolated from many current intervention efforts. The theories in this paper are based on two distinct ideas: 1) that West African specialists in obstetrics and gynecology can become leaders in rural and urban programs to prevent maternal mortality and morbidity, and 2) that a sharing of contemporary knowledge and skills with colleagues from more developed countries allows the specialist in West Africa continually to improve available care and to utilize those aspects of technology that seem most appropriate in their 
setting. Excellence in clinical medicine is desirable in every part of the world. A vision of that excellence must be provided. For these ideas to become reality, a beginning must be made to foster an interest and a commitment on the part of American physicians to become involved in assisting their counterparts in developing countries.

In a recent lecture, Professor Adetokonbo Lucas ${ }^{15}$ addressed the urgent need for the world again to recognize the role of the clinical specialist in health care systems, even in Third World countries. Armed with vast funding from international sources, countries in the past 20 years have been encouraged to run health services "using an army of volunteer health workers, traditional birth attendants and health auxilliaries" in a way that includes "no clearly defined role for the clinical specialist." Lucas openly asked, "Has the pendulum swung too far?" It is maternal mortality that has forced a focus on the inadequacy of approaches to health care that rely solely on village-level interventions and ignore contemporary clinical excellence. Without excellent advanced clinical care, women will continue to die at present rates. Lucas concluded by urging clinical specialists "to redefine their roles in the context of community and national needs, and to take one step beyond and add relevance to excellence."

Can we become involved in a worthwhile way? The answer is obviously "yes." One day, perhaps, we will be able to forget forever the comment made so many years ago in anger: "So it is in Africa. So it will always be."

\section{REFERENCES}

1. Harrison KA. Maternal mortality in developing countries. Br J Obstet Gynaecol 1989;96:1-3.

2. Wilson JB, Tagoe GA. C-sections in Ghana-A ten year review. Presented at the International FIGO Meeting, Singapore, September 1991.

3. Gardiner C. Maternal mortality in rural Ghana. Presented at the Korle Bu Teaching Hospital, Accra, Ghana, January 5, 1991.

4. El Kady AA, Saleh S, Gadalla S, Fortney J, Bayoumi H. Obstetric deaths in Menoufia Governorate, Egypt. Br J Obstet Gynaecol 1989;96:9-14.

5. Ojo OA, Savage VY. A ten year review of maternal mortality rates in the University College Hospital, Ibadan, Nigeria. Am J Obstet Gynecol 1978;118:517-22.

6. Rosenfield A. Maternal mortality in developing countries: An ongoing but neglected epidemic. JAMA 1989;262:376-9.

7. Elkins TE, Drescher C, Martey JO, Anane R. Cesarean delivery in developing countries. In: Phelan JP, Clark SL, eds. Cesarean delivery. London: Elsevier, 1988;521-30.

8. Dobbie BM. An attempt to estimate the true rate of maternal mortality in sixteenth to eighteenth centuries. Med Hist 1982;26:79-90.

9. Kaunitz AH, Rochat RW, Hughes J, Smith JC, Guines DA. Perinatal and maternal mortality in a religious group avoiding obstetric care. Am J Obstet Gynecol 1984;150:826-31.

10. Harrison KA. Child-bearing, health and social priorities: A survey of 22,774 consecutive hospitals births in Zaria, northem Nigeria. Br J Obstet Gynaecol 1985;92S:1119.

11. Balde MD, Bastert G. Decrease in uterine rupture in Conakry, Guinea, by improvements in transfer management. Int J Gynecol Obstet 1990;31:21-4.

12. Ward A. Vesicovaginal fistulas repair in Nigeria. University of Michigan Fistula Symposium, November 5, 1990.

13. World Health Organization. New estimates of maternal mortality. In: Weekly epidemiological record. Geneva: World Health Organization, 1991;66:345-52.

14. Lawson JB. The bight of Benin and beyond: Reflections on obstetrics in the developing world. Int J Obstet Gynecol 1990;34:101-5.

15. Lucas AO. One step beyond: Clinical specialists add excellence to relevance. Third Michael Wood Memorial Lecture, Nairobi, Kenya, March 1991. 